\title{
ENHANCEMENT OF MICROBIAL PIGMENT PRODUCTION FROM MONASCUS RUBER BY SODIUM OCTANOATE ADDITION
}

\author{
${ }^{1}$ Chemical Institute, Federal University of Goiás \\ Avenida Esperança s/n, 74.690-900 Goiânia, Goiás, Brazil \\ ${ }^{2}$ College of Agronomy, Federal University of Goiás \\ Avenida Esperança s/n, 74.690-900 Goiânia, Goiás, Brazil
}

Taynara Álvares Martins ${ }^{1}$, Francielo Vendruscolo ${ }^{2 \bowtie}$

\begin{abstract}
Background. The addition of fatty acids and other molecules to culture media may intensify the production of biomolecules, such as monascus pigments, however, few studies of this have been developed. Thus, the objective of the present study was to investigate the effects of adding sodium octanoate to the culture medium, with a view to increasing the synthesis and production of the pigments produced by Monascus ruber CCT 3802 on solid and submerged cultivations.

Materials and methods. Monacus ruber CCT 3802 was cultivated on solid and submerged media supplemented with different concentrations of sodium octanoate. The radial growth rate of the colonies was obtained from the declivity of the linear regression of the radius of the colonies as a function of cultivation time and the kinetics of submerged cultivations were performed. The filtrate obtained was submitted to scanning spectrophotometry at a range from 350 to $550 \mathrm{~nm}$ and the color parameters were determined by using the CIELAB color system. The data were submitted to a univariate analysis of variance (ANOVA) and the means obtained for each treatment submitted to Tukey's test using Statistica version 5.0 software at a 5\% level of significance.

Results. Sodium octanoate exerted a strong influence on growth and pigment production in solid and submerged cultivations. The values for $L^{*}, a^{*}$ and $b^{*}$ were positive for pigments produced, with regards to colors close to red and yellow. In the media supplemented with $1.0 \mathrm{mM}$ and $1.5 \mathrm{mM}$ of sodium octanoate, the production of red pigments became expressive from 48 hours-cultivation, increasing considerably from the second to the fourth days. This shows that supplementation with sodium octanoate provides a greater production of pigments in a shorter time interval than the control culture, which required 144 hours of cultivation to present a higher value for $\mathrm{AU}_{510 \mathrm{~nm}}$, which directly influenced pigment productivity.

Conclusion. The addition of sodium octanoate exerted a significant influence on both microbial growth and pigment production in both solid and submerged cultivations. The supplementation of the submerged cultures with sodium octanoate was responsible for an expressive production of pigments in just 48 hours, whereas 144 hours were necessary in the absence of sodium octanoate. These results are promising for increasing the productivity of pigment production, including possibilities for application on an industrial scale.
\end{abstract}

Keywords: microbial pigments, solid culture, submerged cultivation, sodium octanoate, microbial pigments 


\section{INTRODUCTION}

Color is one of the acceptability attributes for food products since it leads the consumer to believe that a determined color has a direct relationship with certain sensory aspects such as aroma and texture, and with nutritional quality (Oliveira et al., 2019). Colors are directly connected with various aspects of everyday life and capable of influencing day-to-day decisions.

Since they are aware of the relevance of food and beverage colors, industries use dyes with the objective of increasing acceptability and conquering consumer preference. However, the undesirable mutagenicity and carcinogenic potential of synthetic dyes has led to an increase in the study and development of natural pigments (Morales-Oyervides et al., 2020; Rodriguez-Amaya, 2016). The notoriety that natural dyes have gained is due not only to the worldwide tendency to consume natural products, but also to the functional properties attributed to some of these pigments, such as antioxidant activity and health properties, including anticancer and chemoprotective properties (Dłużewska and Bednarek, 2005; Handa et al., 2019).

Natural pigments come from plants, animals and microorganisms, but few are available in amounts sufficient for commercial use as food and beverage formulations (Palácio-Barrera et al., 2019; Wójciak et al., 2011). The most common natural pigments are obtained from plants, namely carotenoids, chlorophylls, anthocyanins and betalains, but natural dyes can be produced from non-vegetable sources such as animals and microorganisms (Sánchez-Muñoz et al., 2020; Stachowiak, 2014). Food pigments obtained from microorganisms have received much attention in research studies and are beginning to gain space on the food market, including pigments produced by Monascus (Bühler et al., 2015), Aspergillus (Saravanan et al., 2020), Bacillus (Dawoud et al., 2020), Rhodonellum (Bisht et al., 2020), Penicillium (Bouhri et al., 2020) and Talaromyces (Morales-Oyervides et al., 2020).

The production of microbial pigments presents a very attractive biotechnological potential, particularly fungi of the genus Monascus, a filamentous fungus whose main industrial application is related to its ability to produce yellow, orange and red pigments, which have traditionally been used as food dyes in Asian countries (Vendruscolo et al., 2016).
The Monascus pigment producing process is related to various factors such as the type of cultivation (solid or submerged), the microbial species, the $\mathrm{pH}$ value, the nitrogen and carbon sources and other nutrients, the temperature and dissolved oxygen (Agboyibor et al., 2018; Orak et al., 2018; Xu et al., 2021). Thus, various studies are being carried out aimed at potentiating the factors that influence pigment production.

The Monascus pigments constitute a group of metabolites known as azafilones, which are synthesized by the different Monascus species (Huang et al., 2018). The metabolic process starts with the condensation of one mole of acetate with five moles of malonate in the cytosol, leading to the formation of a hexaketide chromophore by the enzyme polyketide synthase, part of the multienzyme complex. Medium chain fatty acids such as octanoic acid are synthesized by the fatty acid pathway and bind to the chromophore structure by a transesterification reaction, generating an orange pigment. The reduction of the orange pigment forms a yellow pigment, whereas the amination of the orange pigment forms a red pigment (Hajjaj et al., 2000).

The addition of fatty acids to culture media may intensify the production of biomolecules, such as monascus pigments, however, few studies have been developed in this area. Thus, the objective of the present study was to investigate the effects of adding sodium octanoate to the culture medium, with a view to increasing the synthesis and production of the pigments produced by Monascus ruber CCT 3802 .

\section{MATERIALS AND METHODS}

\section{Microorganism}

The microorganism used was the filamentous fungus Monascus ruber CCT 3802, obtained from the Tropical Culture Collection of the André Tosello Foundation (Campinas, SP, Brazil) and maintained in potato dextrose agar (PDA; Scharlau, Spain). The culture was maintained on PDA slants in test tubes and in Roux bottles, both sterilized at $121^{\circ} \mathrm{C}$ for 15 minutes. After inoculation, the cultures were incubated in a BOD micro-processed incubator (Marqlabor, Brazil) at 28 $\pm 1^{\circ} \mathrm{C}$ for 10 days and then maintained at $4^{\circ} \mathrm{C}$. 


\section{Solid cultivation}

Cultivation. The radial growth rate of the Monascus ruber CCT 3802 colonies was obtained by supplementation of the PDA culture medium with different concentrations of sodium octanoate $(0.0 \mathrm{mM}, 1.5 \mathrm{mM}$, $3.0 \mathrm{mM}, 4.5 \mathrm{mM}$ and $6.0 \mathrm{mM})$. The culture media were autoclaved at $121^{\circ} \mathrm{C}$ for $15 \mathrm{~min}$. With the aid of a $1.5 \mathrm{~mm}$ sterile loop, a spore suspension was inoculated at the center of each Petri dish. A spore suspension was prepared by adding three loopfuls of Monascus ruber to $1 \mathrm{~mL}$ of $0.2 \%(\mathrm{w} / \mathrm{v})$ bacteriological agar, previously autoclaved at $121^{\circ} \mathrm{C}$ for $15 \mathrm{~min}$. After inoculation, three radii were drawn on the bases of the plates, passing through the point of inoculation, in order to measure the radius of each colony and subsequently calculate the mean radius. The plates were incubated in a BOD incubator (Marqlabor, Brazil) at $28 \pm 2^{\circ} \mathrm{C}$. All experiments were performed in quintuplicate.

Radial growth. The diameters of the Monascus ruber CCT 3802 colonies were measured using a digital pachymeter (Universal, São Paulo, Brazil) every 24 hours. The radial growth rate of the colonies was obtained from the declivity of the linear regression of the radius of the colonies as a function of cultivation time, as shown in equation 1 :

$$
r(t)=a+V_{\mathrm{RG}} \times t
$$

where:

$r(t)$ - the colony radius, $\mathrm{mm}$,

$a$ - the linear regression constant,

$V_{\mathrm{RG}}$ - the radial growth rate, $\mathrm{mm} \mathrm{h}^{-1}$,

$t$ - the cultivation time, $\mathrm{h}$.

The declivities of the linear regression for the different rates obtained were compared using Microsoft Excel $^{\circledR} 2010$ software, and the Tukey's test was used to verify any significant differences between the growth rates obtained from the regression curves, by way of Statistica 7.1 software.

Extraction and quantification of the pigments. At the end of cultivation, the Monascus ruber colonies cultivated in PDA Petri dishes were scraped from the surface and transferred to $125 \mathrm{~mL}$ conical flasks containing $35 \mathrm{~mL} 95^{\circ} \mathrm{GL}$ ethyl alcohol. The samples were submitted to heating in a water bath at $40^{\circ} \mathrm{C}$ for 1 hour, with agitation at $100 \mathrm{rpm}$ (Tecnal TE-421, Brazil), and then vacuum filtered through filter paper (Qualy, Brazil). The filtrate obtained was submitted to scanning spectrophotometry (Shimadzu Espectro UV 1800) in a range from 350 to $550 \mathrm{~nm}$ (Vendruscolo et al., 2016) and the color parameters were determined using the CIELAB color system.

Determination of the color parameters. The color parameters of $L^{*}$ (luminosity - pure white to pure black), $a^{*}$ (intensity of green $(-)$ and red $\left.(+)\right)$ and $b^{*}$ (intensity of blue $(-)$ and yellow $(+))$ were determined by a direct reading of the total transmittance in a colorimeter (ColorQuest ${ }^{\circledR}$ XE, HunterLab, Virginia, USA) using the CIELAB color system. The saturation index or Chroma $\left(C^{*}\right)$ and the hue angle $\left(h_{\mathrm{ab}}\right)$, were determined from equations 2 and 3 , respectively:

$$
\begin{gathered}
C^{*}=\left[\left(a^{*}\right)^{2}+\left(b^{*}\right)^{2}\right]^{1 / 2} \\
h_{\mathrm{ab}}=\tan ^{-1}\left(b^{*} / a^{*}\right)
\end{gathered}
$$

The total color difference $(\Delta E)$ was determined by equation 4:

$$
\Delta E=\left[\left(L^{*}-L_{0}^{*}\right)^{2}+\left(a^{*}-a_{0}^{*}\right)^{2}+\left(b^{*}-b_{0}^{*}\right)^{2}\right]^{1 / 2}
$$

where:

$L_{0}{ }^{*}, a_{0}{ }^{*}, b_{0}{ }^{*}$ are the CIELAB color responses of the experiments whithout adding sodium octanoate.

Biomass determination. The biomass retained on the filter paper after vacuum filtration for pigment extraction was autoclaved at $121^{\circ} \mathrm{C}$ for $15 \mathrm{~min}$ in conical flasks containing $30 \mathrm{~mL}$ of distilled water, and the colonies were separated, dried and weighed on an analytical balance (Marte AY 220, the Philippines) in order to determine the biomass (Oliveira et al., 2019).

\section{Submerged cultivation}

Pre-inoculum. The pre-inoculum was prepared from the spores present in the Roux bottles using $15 \mathrm{~mL}$ of sterile distilled water. The suspension was filtered through sterile gauze and the filtrate used to inoculate conical flasks containing $150 \mathrm{~mL}$ of culture medium composed of $\left(\mathrm{g} \mathrm{L}^{-1}\right)$ : 20.0 glucose, 5.0 glutamate, 5.0 $\mathrm{K}_{2} \mathrm{HPO}_{4}, 5.0 \mathrm{KH}_{2} \mathrm{PO}_{4}, 0.1 \mathrm{CaCl}_{2}, 0.5 \mathrm{MgSO}_{4} \cdot 7 \mathrm{H}_{2} \mathrm{O}$, $0.01 \quad \mathrm{FeSO}_{4} \cdot 7 \mathrm{H}_{2} \mathrm{O}, \quad 0.01 \quad \mathrm{ZnSO}_{4} \cdot 7 \mathrm{H}_{2} \mathrm{O}$ and 0.03 $\mathrm{MnSO}_{4} \cdot \mathrm{H}_{2} \mathrm{O}$. The culture media were autoclaved at $121^{\circ} \mathrm{C}$ for $15 \mathrm{~min}$. The pre-inoculum was incubated 
in an orbital shaker (Tecnal TE-421, Brazil) at $30^{\circ} \mathrm{C}$ for 48 hours with agitation at $120 \mathrm{rpm}$ for subsequent inoculation.

Cultivation. The assays were carried out in Erlenmeyer flasks containing $100 \mathrm{~mL}$ of culture medium with the addition of $10 \mathrm{~mL}$ of pre-inoculum $(\sim 10 \%$ $\mathrm{v} / \mathrm{v}$ ) and incubated in an orbital shaker (Tecnal TE-421 , Brazil) at $30^{\circ} \mathrm{C}$ with agitation at $120 \mathrm{rpm}$. The culture media were prepared according to Vendruscolo et al. (2013) composed of ( $\left.\mathrm{g} \mathrm{L}^{-1}\right): 20.0$ glucose, 5.0 glutamate, $5.0 \mathrm{~K}_{2} \mathrm{HPO}_{4}, 5.0 \mathrm{KH}_{2} \mathrm{PO}_{4}, 0.1 \mathrm{CaCl}_{2}, 0.5$ $\mathrm{MgSO}_{4} \cdot 7 \mathrm{H}_{2} \mathrm{O}, 0.01 \mathrm{FeSO}_{4} \cdot 7 \mathrm{H}_{2} \mathrm{O}, 0.01 \mathrm{ZnSO}_{4} \cdot 7 \mathrm{H}_{2} \mathrm{O}$ and $0.03 \mathrm{MnSO}_{4} \cdot \mathrm{H}_{2} \mathrm{O}$. Sodium octanoate was added to the flasks in the following concentrations: $0.5 \mathrm{mM}$, $1.0 \mathrm{mM}, 1.5 \mathrm{mM}, 2.0 \mathrm{mM}, 2.5 \mathrm{mM}$ and $3.0 \mathrm{mM}$, with no sodium octanoate being added to the control. The culture media were autoclaved at $121^{\circ} \mathrm{C}$ for $15 \mathrm{~min}$. All experiments were performed in triplicate.

Pigment quantification. The pigments were quantified using a Shimadzu Espectro UV 1800 spectrophotometer from the filtrate obtained during biomass determination at a wavelength of $510 \mathrm{~nm}$ corresponding to the absorption of the red pigments (Vendruscolo et al., 2016). The pigments produced by Monascus ruber CCT 3802 were expressed in absorption units $\left(\mathrm{AU}_{510 \mathrm{~mm}}\right)$. The color parameters were determined after 144 hours of cultivation, obtaining the parameters $L^{*}, a^{*}$ and $b^{*}$, measured by total transmittance in a CIELAB colorimeter (ColorQuest ${ }^{\circledR}$ XE, HunterLab, Hunter Associates Laboratory, Inc., Virginia, USA). These values were used to calculate the values of Chroma $\left(C^{*}\right)$, hue angle $\left(h_{\mathrm{ab}}\right)$ and total color difference $(\Delta E)$ from equations 2,3 and 4 , respectively.

Biomass determination. The biomass was quantified by gravimetry and by vacuum filtration through filter paper (Qualy, Brazil), previously dried $\left(70^{\circ} \mathrm{C}\right.$ for 4 hours) and weighed. The material was dried in a microwave oven (LG Eletronics, MS3048GA) for 20 minutes with a power of $180 \mathrm{~W}$ according to the methodology of Costa and Vendruscolo (2017). It was then cooled in a desiccator for 15 minutes and weighed on an analytical balance (Marte AY 220, the Philippines) to determine the biomass.
Glucose determination. The glucose concentration in the cultivation medium was determined by the 3.5 dinitrosalicylic acid method (Miller, 1959), measuring absorption at $540 \mathrm{~nm}$ using a Shimadzu Espectro UV 1800 spectrophotometer and comparing it with a standard curve for glucose in the range from $0 \mathrm{~g} \mathrm{~L}^{-1}$ to $3 \mathrm{~g} \mathrm{~L}^{-1}$.

Kinetic parameters. The maximum specific growth rates during the exponential phase were calculated from the angular coefficient of the slope linearized by the natural logarithm of the residual biomass with time according to equation 5 :

$$
\ln (X)=\ln \left(X_{0}\right)+\mu_{\max } \times t
$$

where:

$X$ - the biomass concentration throughout the exponential phase, $\mathrm{g} \mathrm{L}^{-1}$,

$X_{0}$ - the biomass concentration at the start of the exponential phase, $\mathrm{g} \mathrm{L}^{-1}$,

$\mu_{\max }-$ the maximum specific cell growth rate, $\mathrm{h}^{-1}$,

$t \quad$ - the time, h.

The maximum cell productivity $\left(P_{\text {cells }}\right)$ was calculated from the difference between the greatest cell concentration at a determined instant $t$ and the initial cell concentration, divided by the corresponding time interval according to equation 6 :

$$
P_{\text {cells }}=\left(X_{\max t}-X_{t 0}\right) /\left(t-t_{0}\right)
$$

where:

$P_{\text {cells }}-$ corresponds to the mean cell concentration productivity at the instant of time $t-t_{0}, \mathrm{~g} \mathrm{~L}^{-1} \mathrm{~h}^{-1}$,

$X_{\max t}-$ the maximum biomass formation at the instant of time $t, \mathrm{~g} \mathrm{~L}^{-1}$,

$X_{t 0}-$ is the formation of biomass at time $t_{0}, \mathrm{~g} \mathrm{~L}^{-1}$,

$t$ - the time taken to reach the maximum biomass value, $h$.

The mean pigment productivity $\left(P_{m}\right)$ was calculated from the difference between the maximum pigment concentration $\left(\mathrm{AU}_{510 \mathrm{~nm}}\right)$ at the instant $t$ and the initial pigment concentration, divided by the corresponding time interval according to equation 7 :

$$
P_{m}=\left(\mathrm{AU}_{\max t}-\mathrm{AU}_{t 0}\right) /\left(t-t_{0}\right)
$$

where:

$P_{m} \quad-$ the mean pigment productivity for the instant of time $t-t_{0}, \mathrm{AU}_{510 \mathrm{~mm}} \mathrm{~h}^{-1}$, 
Martins, T. Á., Vendruscolo, F. (2020). Enhancement of microbial pigment production from Monascus ruber by sodium octanoate addition. Acta Sci. Pol. Technol. Aliment., 19(4), 445-456. http://dx.doi.org/10.17306/J.AFS.2020.0870

$\mathrm{AU}_{\text {maxt }}$ - the maximum absorbance units at 510 $\mathrm{nm}$ of pigment at the instant of time $t$, $\mathrm{AU}_{510 \mathrm{~nm}}$,

$\mathrm{AU}_{t 0}$ - the absorbance units at $510 \mathrm{~nm}$ at time $t_{0}$, $\mathrm{AU}_{510 \mathrm{~nm}}$,

$t \quad-$ the time taken to reach the maximum value of absorbance units at $510 \mathrm{~nm}, \mathrm{~h}$,

$t_{0} \quad-$ the time that cultivation started, h.

\section{Statistical analyses}

The data were submitted to a univariate analysis of variance (ANOVA) and the means obtained for each treatment submitted to Tukey's test using Statistica version 5.0 software at a 5\% level of significance.

\section{RESULTS AND DISCUSSION}

Figure 1 presents the radial growth curves of the $\mathrm{Mo}$ nascus ruber colonies cultivated with different sodium octanoate concentrations, and Table 1 shows the equations for the behaviors of the radii of the colonies as a function of cultivation time, the regression coefficients and the radial growth rates. The highest radial growth rate was observed when the Monascus ruber was cultivated in a PDA medium supplemented with $1.5 \mathrm{mM}$ sodium octanoate, where the daily growth rate of the colonies was $0.0695 \pm 0.0017 \mathrm{~mm} \mathrm{~h}^{-1}$, and the lowest radial growth rate was observed when no sodium octanoate was added to the medium, with a value of $0.0504 \pm 0.0051 \mathrm{~mm} \mathrm{~h}^{-1}$. The variation in growth rate between these values corresponded to an increase of $38 \%$ in the fungal growth rate, demonstrating the influence of sodium octanoate on the radial growth rate of Monascus ruber. The statistical analysis showed that colonies cultivated in supplemented media presented significant differences in radial growth rate $(p \leq 0.05)$. The growth was greatest in the culture media supplemented with sodium octanoate at concentrations of $1.5 \mathrm{mM}$ and $3.0 \mathrm{mM}$.

The pigments produced by Monascus ruber cultivated with different sodium octanoate supplementation were extracted and submitted to a spectrophotometric scan and determination of color parameters using the CIELAB color system (Fig. 2 and Table 2). All the analyzed pigments showed an absorption peak at 500 $\mathrm{nm}$, a result characteristic of the presence of red pigments. It can be seen that the concentration of sodium octanoate exerted a strong influence on pigment production, since the absorption values of the pigments produced in the culture media supplemented with sodium octanoate were superior to those of the control.

The pigments produced by Monascus sp. are mixtures of red, yellow and orange-colored polyketides produced by a pathway very similar to that used for

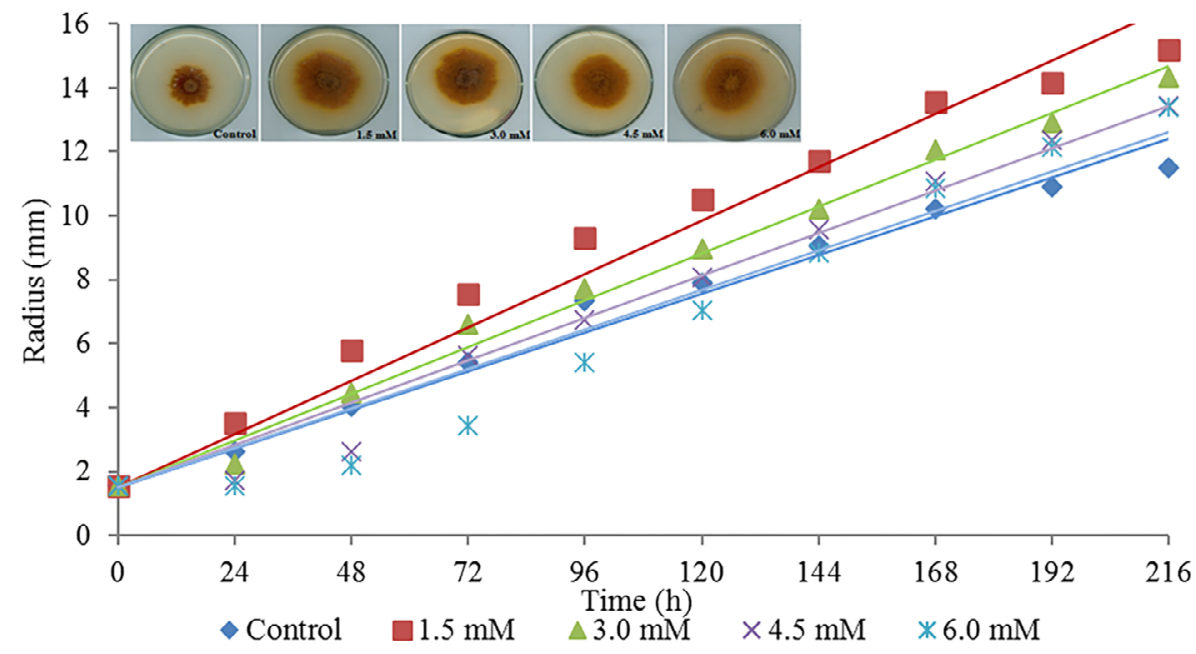

Fig. 1. Radial evolution of the Monascus ruber CCT 3802 colonies cultivated on a PDA medium supplemented with sodium octanoate 
Martins, T. Á., Vendruscolo, F. (2020). Enhancement of microbial pigment production from Monascus ruber by sodium octanoate addition. Acta Sci. Pol. Technol. Aliment., 19(4), 445-456. http://dx.doi.org/10.17306/J.AFS.2020.0870

Table 1. Linear regression equation, regression coefficient $\left(R^{2}\right)$ and radial growth velocity $\left(V_{\mathrm{RG}}\right)$ of the Monascus ruber CCT 3802 colonies cultivated in culture media supplemented with sodium octanoate

\begin{tabular}{cccc}
\hline Sodium octanoate, $\mathrm{mM}$ & Regression equation & $R^{2}$ & $V_{\mathrm{RG}}, \mathrm{mm} \mathrm{h}^{-1}$ \\
\hline 0.0 & $r(t)=0.0504 \times t+1.5$ & 0.9798 & $0.0504 \pm 0.0051^{\mathrm{d}}$ \\
1.5 & $r(t)=0.0695 \times t+1.5$ & 0.9665 & $0.0695 \pm 0.0017^{\mathrm{a}}$ \\
3.0 & $r(t)=0.0610 \times t+1.5$ & 0.9913 & $0.0610 \pm 0.0012^{\mathrm{b}}$ \\
4.5 & $r(t)=0.0554 \times t+1.5$ & 0.9781 & $0.0554 \pm 0.0035^{\mathrm{c}}$ \\
6.0 & $r(t)=0.0515 \times t+1.5$ & 0.9406 & $0.0515 \pm 0.0042^{\mathrm{d}}$ \\
\hline
\end{tabular}

${ }^{a-d}$ Means followed by the same letter in the same column do not differ significantly according to the Tukey test at a $5 \%$ level of significance.

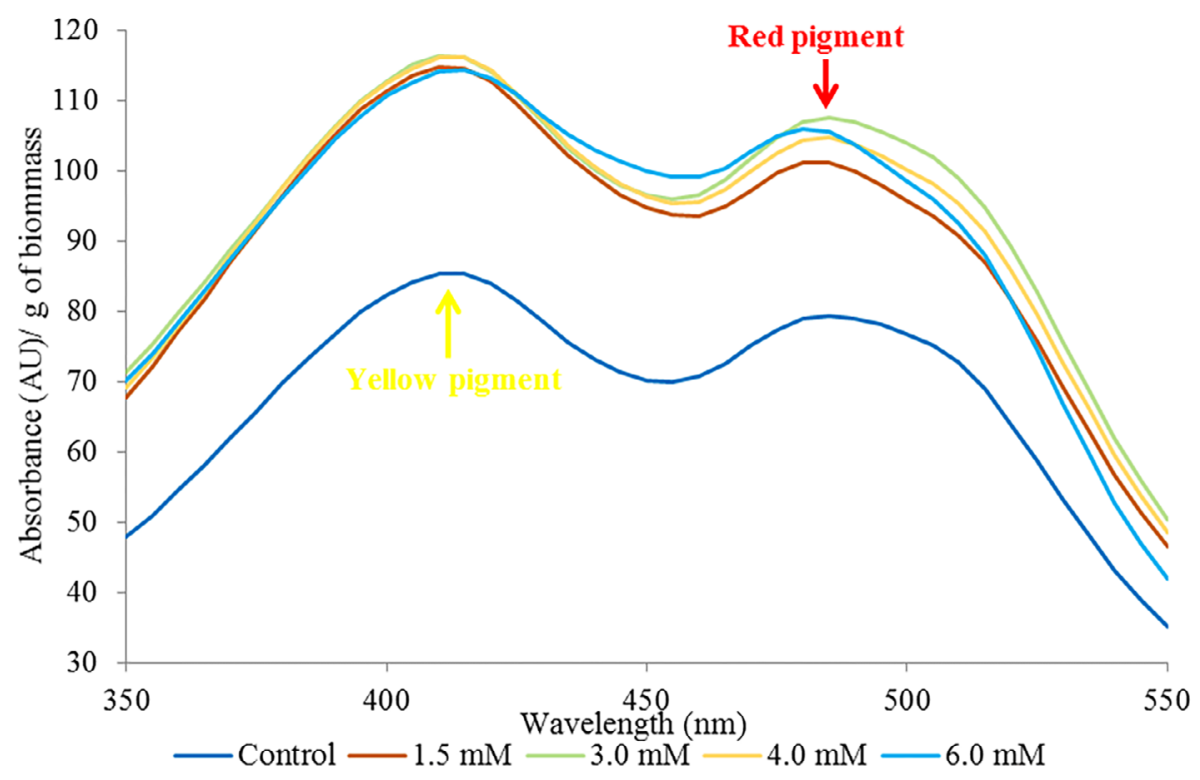

Fig. 2. Absorbance of the pigments produced by Monascus ruber CCT 3802 after 144 hour-cultivation in media supplemented with sodium octanoate

the biosynthesis of fatty acids. The orange pigment is the first pigment biosynthesized, obtained when a fatty acid synthesized by the fatty acid metabolic pathway binds to the chromophore structure by way of a transesterification reaction (Evans and Wang, 1984). This suggests that the addition of the fatty acid to the culture medium impedes the formation of new fatty acid molecules, a process occurring naturally so that the fungus economizes energy, thus favoring the biosynthesis of pigments by Monascus ruber.

The values $L^{*}, a^{*}$ and $b^{*}$ were positive for all the pigments produced, indicating that when plotted in a system with polar coordinates, all the values can be found available in the first quadrant, that is referring to colors close to red and yellow. The values $a^{*}$ were between $55.16 \pm 0.53$ and $60.70 \pm 0.89$, indicating a red 
Martins, T. Á., Vendruscolo, F. (2020). Enhancement of microbial pigment production from Monascus ruber by sodium octanoate addition. Acta Sci. Pol. Technol. Aliment., 19(4), 445-456. http://dx.doi.org/10.17306/J.AFS.2020.0870

Table 2. CIELAB color responses of the pigments produced by Monascus ruber CCT 3802 cultivated in solid media with different concentrations of sodium octanoate

\begin{tabular}{lcccccc}
\hline \multirow{2}{*}{ Sodium octanoate, $\mathrm{mM}$} & \multicolumn{5}{c}{ CIELAB } \\
\cline { 2 - 7 } & \multicolumn{1}{c}{$L^{*}$} & $a^{*}$ & $b^{*}$ & $C^{*}$ & $h_{\mathrm{ab}}$ & $\Delta E$ \\
\hline 0.0 & $38.43 \pm 5.17^{\mathrm{a}}$ & $60.70 \pm 0.89^{\mathrm{a}}$ & $65.23 \pm 7.97^{\mathrm{a}}$ & $89.29 \pm 5.56^{\mathrm{a}}$ & $47.1 \pm 3.64^{\mathrm{a}}$ & - \\
1.5 & $22.94 \pm 0.77^{\mathrm{b}}$ & $55.16 \pm 0.53^{\mathrm{b}}$ & $39.37 \pm 1.31^{\mathrm{b}}$ & $67.78 \pm 1.19^{\mathrm{c}}$ & $35.5 \pm 0.65^{\mathrm{c}}$ & 30.65 \\
3.0 & $25.70 \pm 2.20^{\mathrm{b}}$ & $57.26 \pm 1.72^{\mathrm{c}}$ & $44.14 \pm 3.83^{\mathrm{c}}$ & $72.33 \pm 3.70^{\mathrm{b}}$ & $37.6 \pm 1.60^{\mathrm{b}}$ & 24.86 \\
4.5 & $23.59 \pm 1.98^{\mathrm{b}}$ & $55.16 \pm 1.55^{\mathrm{b}}$ & $40.48 \pm 3.45^{\mathrm{b}}$ & $68.45 \pm 3.28^{\mathrm{c}}$ & $36.3 \pm 1.55^{\mathrm{c}}$ & 29.38 \\
6.0 & $24.81 \pm 0.95^{\mathrm{b}}$ & $56.18 \pm 0.79^{\mathrm{b}}$ & $42.57 \pm 1.60^{\mathrm{b}}$ & $70.50 \pm 1.57^{\mathrm{c}}$ & $37.2 \pm 0.70^{\mathrm{b}}$ & 26.81 \\
\hline
\end{tabular}

${ }^{\mathrm{a}-\mathrm{c}}$ Means followed by the same letter in the same column do not differ significantly according to the Tukey test at a $5 \%$ level of significance. $\Delta E$ is the total color difference of the experiment compared to the control without the addition of sodium octanoate.

color. The parameter $C^{*}$ presented values between 67 and 89 , showing how intense the red color was. The values $h_{\mathrm{ab}}$ were between 35 and 47, indicating that the color of the pigment varied from dark orange to intense red. Shi et al. (2015) studied the color characteristics of Monascus pigments by controlling parameters such as $\mathrm{pH}$ value and nitrogen sources, and obtained a reddish-orangey coloration with values for $h_{\mathrm{ab}}$ of 42.62 and for the parameter $L^{*}$ of 38.85 .

Having identified the positive influence of supplementing the culture medium on the pigment production and growth of Monascus ruber, submerged cultivations were developed with media supplemented with up to $3.0 \mathrm{mM}$ of sodium octanoate, since when using solid state cultivations the higher values inhibited microbial growth. The culture containing $3.0 \mathrm{mM}$ sodium octanoate did not form biomass or produce pigments, and so the data were not reported.

During the initial phase of cultivation of Monascus ruber, carbon and nitrogen were used as the substrates to produce the primary metabolites, energy, carbon dioxide and water. In the final growth phase, the fungi produce secondary metabolites such as pigments, citrinin and lovastatin (Pattanagul et al., 2007). It can be seen that no glucose consumption was intense in the first 24 hours for the cultures supplemented with $0.5 \mathrm{mM}, 1.0 \mathrm{mM}$ and $2.5 \mathrm{mM}$ of sodium octanoate, whereas for the concentrations of $1.5 \mathrm{mM}, 2.0 \mathrm{mM}$ and the control, glucose consumption was not observed during the first 24 hours of cultivations (Fig. 3a). The glucose consumption data are important, since, after the growth phase, when the Monascus ruber uses the carbon and nitrogen sources to produce primary metabolites, pigments are produced.

With respect to biomass production, it can be seen that the cultures supplemented with $1.0 \mathrm{mM}$ and $1.5 \mathrm{mM}$ of sodium octanoate showed greater biomass production of $4.68 \mathrm{~g} \mathrm{~L}^{-1}$ and $4.94 \mathrm{~g} \mathrm{~L}^{-1}$, respectively, after 144 hours of cultivation, whereas biomass production by the control culture, with no addition of sodium octanoate, was much smaller, reaching a maximum of $2.42 \mathrm{~g} \mathrm{~L}^{-1}$ after 144 hours of cultivation, as shown in Figure $3 b$.

After 90 hours of cultivation, Hajjaj et al. (2000) observed a maximum biomass production by Monascus ruber of $1.8 \mathrm{~g} \mathrm{~L}^{-1}$ using a culture medium consisting of $5 \mathrm{~g} \mathrm{~L}^{-1}$ of glucose, $5 \mathrm{~g} \mathrm{~L}^{-1}$ of monosodium glutamate and salts. An evaluation of biomass formation is important since the production of red pigments is partially associated with cell growth.

In the media supplemented with $1.0 \mathrm{mM}$ and $1.5 \mathrm{mM}$ of sodium octanoate, the formation of red pigments (Fig. 3c) became expressive from 48 hours of cultivation, increasing considerably from the second to the fourth days. It can be seen that the culture media supplemented with $1.0 \mathrm{mM}$ and $1.5 \mathrm{mM}$ produced more pigment after 96 hours of cultivation, reaching 4.10 and $3.55 \mathrm{AU}_{510 \mathrm{~nm}}$ (increases of $52 \%$ and $46 \%$ ), respectively in relation to the control. After 144 hours of cultivation, the greatest absorbance was observed for the culture without the addition of sodium octanoate $\left(4.78 \mathrm{AU}_{510 \mathrm{~nm}}\right)$, and in the cultures containing sodium 


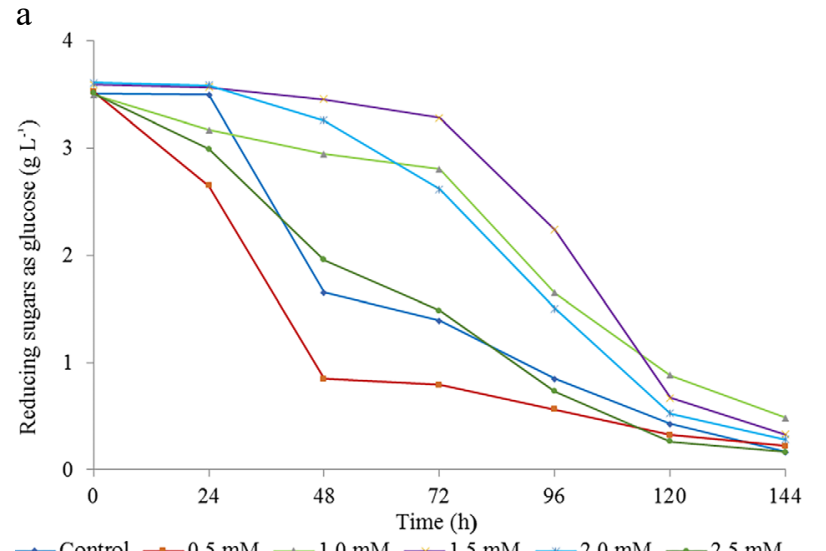

b
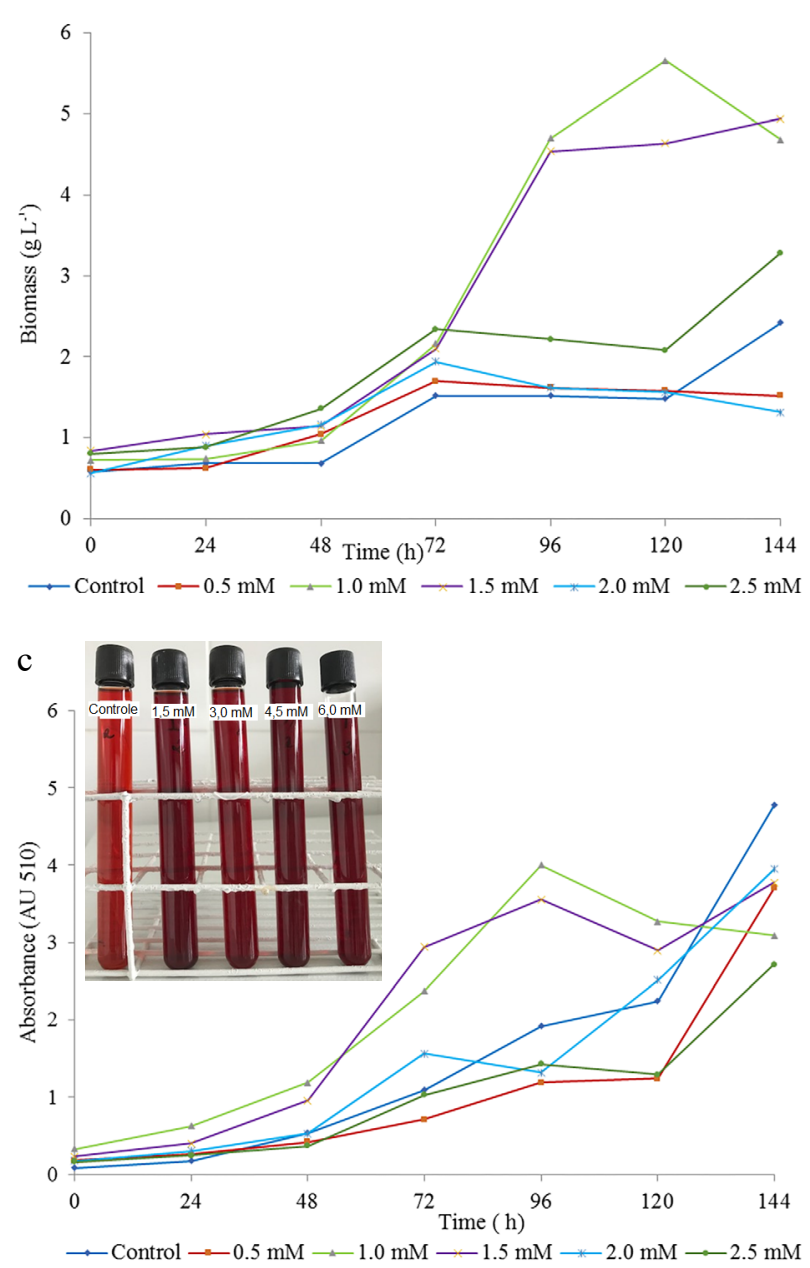

Fig. 3. Submerged fermentation of Monascus ruber CCT 3802 cultivated on supplemented media with sodium octanoate at different concentrations: $\mathrm{a}$ - reducing sugars, $\mathrm{b}-$ biomass production, $\mathrm{c}-$ pigment production octanoate the highest absorbance values were found for the concentrations of $0.5 \mathrm{mM}\left(3.70 \mathrm{AU}_{510 \mathrm{~nm}}\right), 1.5 \mathrm{mM}$ (3.77 $\left.\mathrm{AU}_{510 \mathrm{~nm}}\right)$ and $2.0 \mathrm{mM}\left(3.95 \mathrm{AU}_{510 \mathrm{~nm}}\right)$. This shows that supplementation with sodium octanoate provides a greater production of pigments in a shorter time interval than the control culture, which required 144 hours of cultivation to present a higher value for $\mathrm{AU}_{510 \mathrm{~nm}}$, directly influencing pigment productivity.

Table 3 shows the kinetic results obtained for pigment production by Monascus ruber cultured in media supplemented with different sodium octanoate concentrations. The highest growth rates were found for the cultures supplemented with $0.5 \mathrm{mM}, 1.0 \mathrm{mM}$ and $2.5 \mathrm{mM}$ of sodium octanoate, giving values of approximately $0.021,0.022$ and $0.020 \mathrm{~h}^{-1}$, respectively. Costa and Vendruscolo (2017) observed a maximum growth rate of $0.017 \mathrm{~h}^{-1}$ for a culture containing lactose as the substrate, a value close to those found in the present study. The maximum pigment production was reached by the control culture after 144 hours of cultivation (4.782 $\mathrm{AU}_{510 \mathrm{~nm}}$ ). However, the culture containing $1.0 \mathrm{mM}$ of sodium octanoate reached a maximum production of red pigments (4.103 $\mathrm{AU}_{510 \mathrm{~nm}}$ ) in just 96 hours of cultivation, showing that supplementation at this concentration was efficient, since the values for $P_{\text {cells }}$ and $P_{m}$ for this culture were greater than the values obtained by the control culture, the productivity of red pigments for this concentration being about 29\% higher than that of the control culture.

Hamano et al. (2005) studied the cultivation of different Monascus strains and observed that the growth phase ended after 20 to 25 hours of cultivation and that the production of red pigments was partially associated with growth. The maximum biomass production was between 5.9 and $8.8 \mathrm{~g} \mathrm{~L}^{-1}$, with the maximum red pigment production varying between $8.0 \mathrm{AU}$ and 20.4 AU. Hajjaj et al. (2000) observed that the addition of medium or long chain fatty acids could inhibit the formation of citrinin but could contribute to the production of pigments. They also perceived that supplementation of the medium with $0.5 \mathrm{mM}$ of sodium octanoate doubled the pigment production.

Figure 4 shows the color change of the culture media as a function of time cultivation. Supplementation with $3 \mathrm{mM}$ of sodium octanoate exerted an inhibitory effect, showed no microbial growth or glucose consumption, and consequently there was no pigment production. 
Martins, T. Á., Vendruscolo, F. (2020). Enhancement of microbial pigment production from Monascus ruber by sodium octanoate addition. Acta Sci. Pol. Technol. Aliment., 19(4), 445-456. http://dx.doi.org/10.17306/J.AFS.2020.0870

Table 3. Kinetic parameters of the cultures developed by Monascus ruber CCT 3802 in culture media supplemented with sodium octanoate

\begin{tabular}{lcccccc}
\hline \multirow{2}{*}{ Kinetic parameters } & \multicolumn{5}{c}{ Sodium octanoate, $\mathrm{mM}$} \\
\cline { 2 - 7 } & 0.0 & 0.5 & 1.0 & 1.5 & 2.0 & 2.5 \\
\hline$\mu_{\text {max }}, \mathrm{h}^{-1}$ & 0.010 & 0.021 & 0.022 & 0.017 & 0.016 & 0.020 \\
Maximum absorbance, $\mathrm{AU}_{510 \mathrm{~nm}}$ & 4.782 & 3.706 & 4.103 & 3.776 & 3.952 & 2.714 \\
$P_{\text {cells }}, \mathrm{g} \mathrm{L}^{-1} \mathrm{~h}^{-1}$ & 0.017 & 0.024 & 0.047 & 0.034 & 0.027 & 0.032 \\
$P_{m}, \mathrm{AU}_{510 \mathrm{~nm}} \mathrm{~h}^{-1}$ & 0.027 & 0.024 & 0.038 & 0.025 & 0.026 & 0.018 \\
\hline
\end{tabular}

$\mu_{\max }-$ maximum specific velocity, $P_{\text {cells }}-$ maximum cell productivity, $P_{M}-$ maximum pigment productivity.

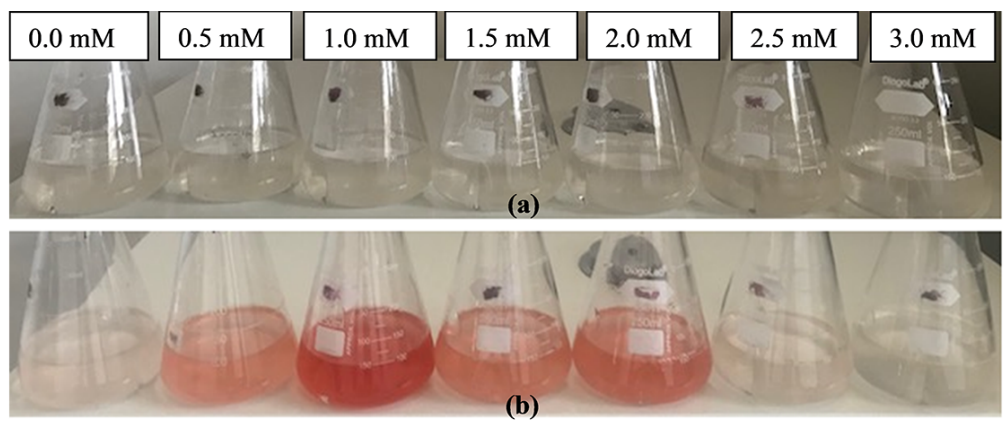

Fig. 4. Color evolution of the culture media
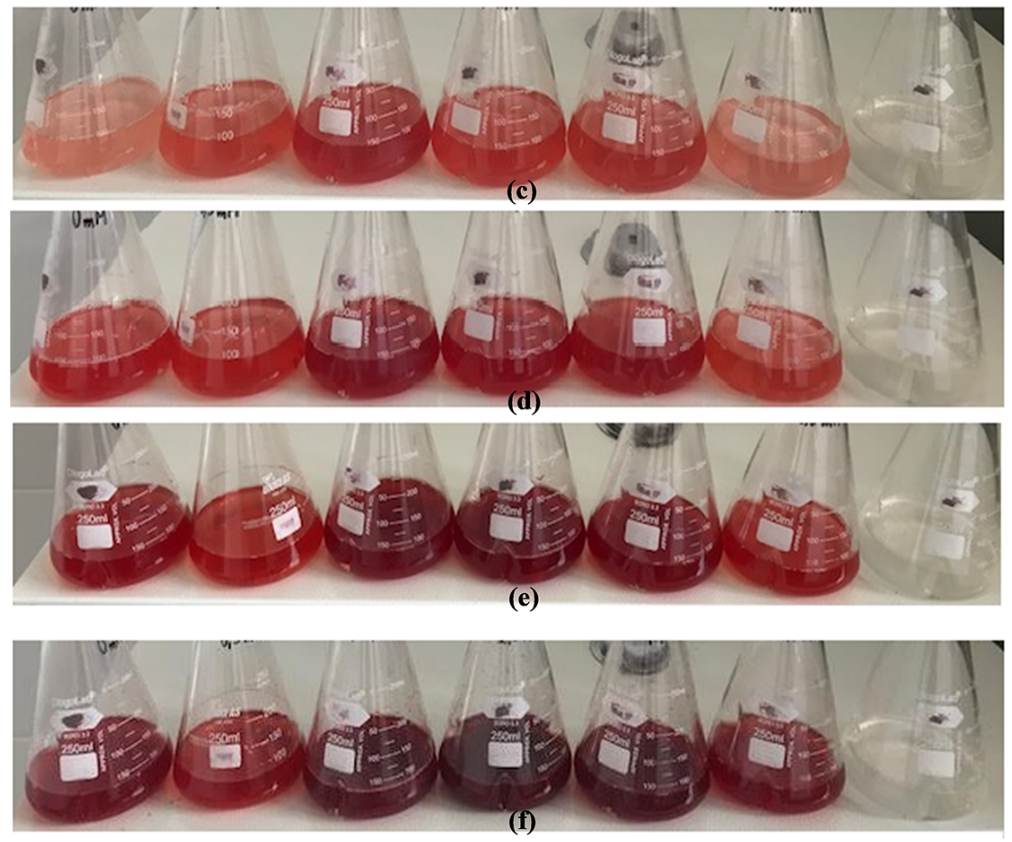

supplemented with sodium octanoate and cultivated by Monascus ruber CCT 3802: $\mathrm{a}-0$ hour, $\mathrm{b}-24$ hours, $\mathrm{c}-48$ hours, $\mathrm{d}-72$ hours, e - 96 hours, $\mathrm{f}-120$ hours, $\mathrm{g}-144$ hours

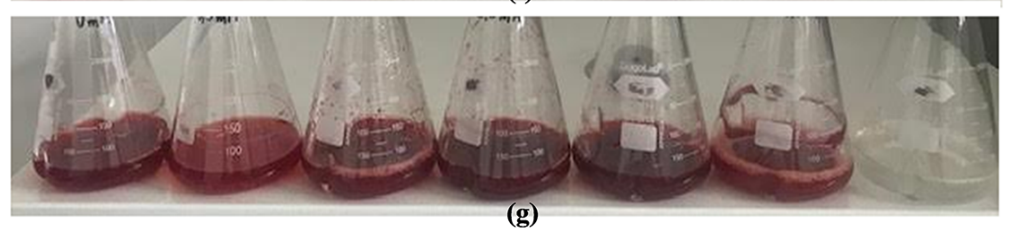


Martins, T. Á., Vendruscolo, F. (2020). Enhancement of microbial pigment production from Monascus ruber by sodium octanoate addition. Acta Sci. Pol. Technol. Aliment., 19(4), 445-456. http://dx.doi.org/10.17306/J.AFS.2020.0870

Table 4. CIELAB color responses of the pigments produced by Monascus ruber CCT 3802 cultivated in submerged cultivation media supplemented with sodium octanoate

\begin{tabular}{|c|c|c|c|c|c|c|}
\hline \multirow{2}{*}{$\begin{array}{l}\text { Sodium } \\
\text { octanoate } \\
\mathrm{mM}\end{array}$} & \multicolumn{6}{|c|}{ CIELAB } \\
\hline & $L^{*}$ & $a^{*}$ & $b^{*}$ & $C^{*}$ & $h_{\mathrm{ab}}$ & $\Delta E$ \\
\hline 0.0 & $37.62 \pm 0.05^{\mathrm{d}}$ & $65.70 \pm 0.16^{\mathrm{a}}$ & $64.69 \pm 0.06^{\mathrm{d}}$ & $92.20 \pm 0.12^{\mathrm{b}}$ & $43.77 \pm 0.08^{c}$ & - \\
\hline 0.5 & $45.48 \pm 0.03^{\mathrm{a}}$ & $65.92 \pm 0.06^{\mathrm{a}}$ & $74.49 \pm 0.24^{b}$ & $99.47 \pm 0.21^{\mathrm{a}}$ & $48.49 \pm 0.07^{\mathrm{a}}$ & 12.64 \\
\hline 1.0 & $39.81 \pm 0.03^{c}$ & $64.46 \pm 0.17^{\mathrm{b}}$ & $68.15 \pm 0.16^{\mathrm{c}}$ & $93.81 \pm 0.11^{\mathrm{c}}$ & $46.58 \pm 0.13^{\mathrm{b}}$ & 4.37 \\
\hline 1.5 & $31.98 \pm 0.03^{\mathrm{e}}$ & $62.62 \pm 0.18^{c}$ & $54.91 \pm 0.11^{\mathrm{e}}$ & $83.28 \pm 0.15^{\mathrm{d}}$ & $41.25 \pm 0.10^{\mathrm{d}}$ & 11.71 \\
\hline 2.0 & $30.41 \pm 0.09^{\mathrm{f}}$ & $59.55 \pm 0.28^{d}$ & $52.16 \pm 0.27^{\mathrm{f}}$ & $79.16 \pm 0.38^{\mathrm{e}}$ & $41.21 \pm 0.04^{\mathrm{d}}$ & 15.39 \\
\hline 2.5 & $44.57 \pm 0.04^{b}$ & $65.96 \pm 0.32^{\mathrm{a}}$ & $75.07 \pm 0.11^{\mathrm{a}}$ & $99.93 \pm 0.13^{\mathrm{a}}$ & $48.69 \pm 0.18^{\mathrm{a}}$ & 12.63 \\
\hline
\end{tabular}

${ }^{\mathrm{a}-\mathrm{f}}$ Means followed by the same letter in the same column do not differ significantly according to the Tukey test at a $5 \%$ level of significance. $\Delta E$ is the total color difference of the experiment compared to the control without the addition of sodium octanoate.

After 24 hours of cultivation the colors of the media supplemented with $0.5 \mathrm{mM}, 1.0 \mathrm{mM}, 1.5 \mathrm{mM}$ and $2.0 \mathrm{mM}$ of sodium octanoate were already presenting a reddish coloration, whereas the control culture and that supplemented with $2.5 \mathrm{mM}$ of sodium octanoate only presented a slightly reddish color from 48 hours of cultivation. At the end of cultivation (144 hours), all the cultivations studied had a similar appearance.

Table 4 shows that all the values for $L^{*}$ were significantly different $(p \leq 0.05)$ from each other, and the pigments produced in the cultivations containing 0.5 $\mathrm{mM}$ and $2.5 \mathrm{mM}$ were lighter and less red than the others. The value $C^{*}$ and $h_{\mathrm{ab}}$ confirmed the purity of the color and the variation between light and intense red. The values obtained for the $h_{\mathrm{ab}}$ angles of all the cultures were close, demonstrating a red coloration.

\section{CONCLUSION}

The addition of sodium octanoate exerted a significant influence on both microbial growth and pigment production in both solid and submerged cultivations. The study revealed that the addition of $1.5 \mathrm{mM}$ sodium octanoate to the potato dextrose agar could increase the velocity of radial growth of the Monascus ruber colonies up to $38 \%$ when compared to the control culture. Supplementation of the submerged cultures with sodium octanoate was responsible for an expressive production of pigments in just 48 hours, whereas 144 hours were necessary in the absence of sodium octanoate. These results are promising for increasing the productivity of pigment production, including possibilities for application on an industrial scale.

\section{ACKNOWLEDGEMENTS}

The authors gratefully acknowledge the Coordenação de Aperfeiçoamento de Pessoal de Nível Superior (CAPES - Committee for Professional Training of Higher Education Staff), for the research scholarship granted.

\section{REFERENCES}

Agboyibor, C., Kong, W. B., Chen, D., Zang, A. M., Niu, S. Q. (2018). Monascus pigments production, composition, bioactivity and its application: A review. Biocatal. Agric. Biotechnol., 16, 433-447. https://doi.org/10.1016/j. bcab.2018.09.012

Bisht, G., Srivastava, S., Kulshreshtha, R., Sourirajan, A., Baumler, D. J., Dev, K. (2020). Applications of red pigments from psychrophilic Rhodonellum psychrophilum GL8 in health, food and antimicrobial finishes on textiles. Proc. Biochem., 94, 15-29. https://doi. org/10.1016/j.procbio.2020.03.021

Bouhri, Y., Askun, T., Tunca, B., Deniz, G., Aksoy, S. A., Mutlu, M. (2020). The orange-red pigment from Penicillium mallochii: Pigment production, optimization, and pigment efficacy against Glioblastoma cell lines. Biocatal. Agric. Biotechnol., 23, 101451. https://doi. org/10.1016/j.bcab.2019.101451 
Martins, T. Á., Vendruscolo, F. (2020). Enhancement of microbial pigment production from Monascus ruber by sodium octanoate addition. Acta Sci. Pol. Technol. Aliment., 19(4), 445-456. http://dx.doi.org/10.17306/J.AFS.2020.0870

Bühler, R. M. M., Müller, B. L., Moritz, D. E., Vendruscolo, F., Oliveira, D., Ninow, J. L. (2015). Influence of light intensity on growth and pigment production by Monascus ruber in submerged fermentation. Appl. Biochem. Biotechnol., 176, 1277-1289. https://doi.org/10.1007/ s12010-015-1645-8

Costa, J. P. V., Vendruscolo, F. (2017). Production of red pigments by Monascus ruber CCT 3802 using lactose as a substrate. Biocatal. Agric. Biotechnol., 11, 50-55. https://doi.org/10.1016/j.bcab.2017.05.010

Dawoud, T. M., Alharbi, N. S., Theruvinthalakal, A. M., Thekkangil, A., Kadaikunnan, S., Khaled, J. M., ..., Rajaram, S. K. (2020). Characterization and antifungal activity of the yellow pigment produced by a Bacillus sp. DBS4 isolated from the lichen Dirinaria agealita. Saudi J. Biol. Sci., 27, 1403-1411. https://doi.org/10.1016/j. sjbs.2019.11.031

Dłużewska, E., Bednarek, P. (2005). Effect of water plant extracts addition on the oxidative stability of meat products. Acta Sci. Pol. Technol. Aliment., 4(2), 59-69.

Evans, P. J., Wang, H. Y. (1984). Pigment production from immobilized Monascus ssp. Utilizing polymeric resin adsorption. Appl. Environ. Microbiol., 47, 1323-1326.

Hajjaj, H., Blanc, P., Groussac, E., Uribelarrea, J. L., Goma, G., Loubiere, P. (2000). Kinetic analysis of red pigment and citrinin production by Monascus ruber as a function of organic acid accumulation. Enzyme Microb. Technol., 27, 619-625. https://doi.org/10.1016/S01410229(00)00260-X

Hamano, P. S., Orozco, S. F. B. M., Kilikian, B. V. (2005). Concentration determination of extracellular and intracellular red pigments produced by Monascus spp. Braz. Arch. Biol. Technol., 48, 43-49. http://dx.doi. org/10.1590/S1516-89132005000400006

Handa, C. L., Lima, F. S., Guelfi, M. F. G, Fernandes, M. S., Georgetti, S. R., Ida, E. I. (2019). Parameters of the fermentation of soybean flour by Monascus purpureus or Aspergillus oryzae on the production of bioactive compounds and antioxidant activity. Food Chem., 271, 274 283. https://doi.org/10.1016/j.foodchem.2018.07.188

Huang, J., Liao, N. Q., Li, H. (2018). Linoleic acid enhance the production of moncolin $\mathrm{K}$ and red pigments in Monascus ruber by activating mokH and mokA, and by accelerating cAMP-PkA pathway. Int. J. Biol. Macromol., 109, 950-954. https://doi.org/10.1016/j.ijbiomac.2017.11.074

Miller, G. L. (1959). Use of dinitrosalicylic acid reagent for determination of reducing sugar. Anal. Chem., 31, 426-428. https://doi.org/10.1021/ac60147a030
Morales-Oyervides, L., Ruiz-Sánchez, J. P., Oliveira, J. C., Sousa-Gallagher, M. J., Méndez-Zavala, Giuffrida, D., ..., Montañez, J. (2020). Biotechnological approaches for the production of natural colorants by Talaromyces/ Penicillium: A review. Biotechnol. Adv., 43, 107601. https://doi.org/10.1016/j.biotechadv.2020.107601

Oliveira, C. F. D., Costa, J. P. V., Vendruscolo, F. (2019). Maltose syrup residue as the substrate for Monascus pigments production. Biocatal. Agric. Biotechnol., 18, 101101. https://doi.org/10.1016/j.bcab.2019.101101

Orak, T., Caglar, O., Ortuce, S., Ozkan, H., Taskin, M. (2018). Chicken feather peptone: A new alternative nitrogen source for pigment production by Monascus purpureus. J. Biotechnol., 271, 56-62. https://doi. org/10.1016/j.jbiotec.2018.02.010

Palácio-Barrera, A. M., Areiza, D., Zapata, P., Atehortúa, L., Correa, C., Peñuela-Vásquez, M. (2019). Induction of pigment production through media composition, abiotic and biotic factors in two filamentous fungi. Biotechnol. Rep., 21, e00308, https://doi.org/10.1016/j.btre.2019. e00308

Pattanagul, P., Pinthong, R., Phianmongkhol, A., Leksawasdi, N. (2007). Review of angkak production (Monascus purpureus). Chiang Mai J. Sci., 34, 319-328.

Rodriguez-Amaya, D. B. (2016). Natural food pigments and colorants. Curr. Opin. Food Sci., 7, 20-26. https://doi. org/10.1016/j.cofs.2015.08.004

Sánchez-Muñoz, S., Mariano-Silva, G., Leite, M. O., Mura, F. B., Verma, M. L., Silva, S. S., Chandel, A. K. (2020). Production of fungal and bacterial pigments and their applications. In M. L. Verma, A. K. Chandel (Eds.), Biotechnological production of bioactive compounds (pp. 327-361). Elsevier. https://doi.org/10.1016/B978-0444-64323-0.00011-4

Saravanan, A., Jayasree, R., Kumar, P. S., Varjani, S., Hemavathy, R. V., Jeevanantham, S., Yaashikaa, P. R. (2020). Production of pigment using Aspergillus tamarii: New potentials for synthesizing natural metabolites. Environ. Technol. Innov., 19, 100967. https://doi.org/10.1016/j. eti.2020.100967

Shi, K., Song, D., Chen, G., Pistolozzi, M., Wu, Z., Quan, L. (2015). Controlling composition and color characteristics of Monascus pigments by $\mathrm{pH}$ and nitrogen sources in submerged fermentation. J. Biosci. Bioeng., 120, 145-154. https://doi.org/10.1016/j.jbiosc.2015.01.001

Stachowiak, B. (2014). Astaxanthin synthesis by Xanthophyllomyces dendrorhous DSM 5626 and its astaxanthin overproducing mutants on xylose media under different illumination. Acta Sci. Pol. Technol. Aliment., 13(3), 279-288. 
Martins, T. Á., Vendruscolo, F. (2020). Enhancement of microbial pigment production from Monascus ruber by sodium octanoate addition. Acta Sci. Pol. Technol. Aliment., 19(4), 445-456. http://dx.doi.org/10.17306/J.AFS.2020.0870

Vendruscolo, F., Müller, B. L., Moritz, D. E., Oliveira, D., Schmidell, W., Ninow, J. L. (2013). Thermal stability of natural pigments produced by Monascus ruber in submerged fermentation. Biocatal. Agric. Biotechnol., 2, 278-284. https://doi.org/10.1016/j.bcab.2013.03.008 Vendruscolo, F., Schmidell, W., Moritz, D. E., Bühler, R. M. M., Oliveira, D., Ninow, J. L. (2016). Isoelectric point of amino acid: Importance for monascus pigment production. Biocatal. Agric. Biotechnol., 5, 179-185. https:// doi.org/10.1016/j.bcab.2015.12.006
Wójciak, K. M., Dolatowski, Z., Okoń, A. (2011). Effect of water plant extracts addition on the oxidative stability of meat products. Acta Sci. Pol. Technol. Aliment., 10(2), $175-188$.

Xu, Y., Wang, X., Liu, X., Li, X., Zhang, C., Li, W., ..., Sun, B. (2021). Discovery and development of a novel shortchain fatty acid ester synthetic biocatalyst under aqueous phase from Monascus purpureus isolated from Baijiu. Food Chem., 338, 128025. https://doi.org/10.1016/j. foodchem.2020.128025 